\title{
Phenotypic and molecular characterization of CTX-M-14 extended-spectrum $\beta$-lactamase and plasmid-mediated ACT-like AmpC $\beta$-lactamase produced by Klebsiella pneumoniae isolates from chickens in Henan Province, China
}

\author{
H. Wu, B.-G. Liu, J.-H. Liu, Y.-S. Pan, L. Yuan and G.-Z. Hu \\ Department of Pharmacology and Toxicology, \\ College of Animal Husbandry and Veterinary Science, \\ Henan Agricultural University, Zhengzhou, P.R. China \\ Corresponding author: G.-Z. Hu \\ E-mail: yaollab@163.com.
}

Genet. Mol. Res. 11 (3): 3357-3364 (2012)

Received March 26, 2012

Accepted June 14, 2012

Published September 24, 2012

DOI http://dx.doi.org/10.4238/2012.September.24.1

\begin{abstract}
Extended-spectrum $\beta$-lactamases (ESBLs) and AmpC $\beta$-lactamases produced by a clinical isolate of Klebsiella pneumoniae from chickens were detected with confirmatory phenotypic tests of the Clinical and Laboratory Standards Institute. The minimum inhibitory concentrations of 18 antibacterial drugs against $K$. pneumoniae were determined by the 2 -fold microdilution method. The genotype and subtype of the ESBL-producing and AmpC $\beta$-lactamase-producing $K$. pneumoniae isolate were identified by PCR amplification of the enzymeencoding genes followed by DNA sequencing analysis. K. pneumoniae $\mathrm{K}_{1}$ isolate was an ESBL-producing and AmpC $\beta$-lactamase-producing bacteria with high resistance to $\beta$-lactam antibiotics, such as penicillins, third-generation cephalosporins, fluoroquinolones, and aminoglycosides. The sequence analysis showed that $K$. pneumoniae $\mathrm{K}_{1}$ harbored TEM-type, SHV-type, CTX-M-type, and ACT-type AmpC $\beta$-lactamase nucleotide
\end{abstract}


sequences. The TEM-type sequence was designated as TEM-1; the SHVtype sequence was designated as SHV-11; the CTX-M-type sequence was designated as CTX-M-14. Compared with the ACT-like sequence (EF078894), the ACT-type sequence was characterized by 8 nucleotide mutations $\left(\mathrm{A}^{75} \mathrm{G}, \mathrm{C}^{84} \mathrm{G}, \mathrm{T}^{90} \mathrm{C}, \mathrm{A}^{105} \mathrm{G}, \mathrm{G}^{213} \mathrm{~A}, \mathrm{G}^{246} \mathrm{~A}, \mathrm{C}^{309} \mathrm{~T}\right.$, and $\left.\mathrm{T}^{315} \mathrm{C}\right)$. Only one mutation at position 75 led to an amino acid substitution (Asn28Lys). The $b l a_{\mathrm{ACT}}$ type was an ACT-like derivative.

Key words: Klebsiella pneumoniae; AmpC $\beta$-lactamase; Genotype; Extended spectrum $\beta$-lactamases

\section{INTRODUCTION}

$\beta$-lactam antibiotics, such as penicillins and cephalosporins, have been extensively used in the control of bacterial diseases in veterinary medicine. As such, in recent years, bacterial drug resistance has become a growing problem worldwide. The production of $\beta$-lactamases is a main mechanism for resistance of Gram-negative bacteria to $\beta$-lactams, such as extendedspectrum $\beta$-lactamases (ESBLs) and AmpC $\beta$-lactamases (Lavigne et al., 2004). ESBLs have spread in many regions of the world and presently consist of over 500 variants (http://www. lahey.org/Studies). These enzymes are mainly produced by members of the Enterobacteriaceae family, most commonly by Klebsiella pneumoniae and Escherichia coli strains (Sirot, 1995). Recently, the most common ESBL genotype has been identified all over the world (De Champs et al., 2000; Winokur et al., 2001). A typical characteristic of ESBLs is their ability to hydrolyze oxyiminocephalosporins and aztreonam while being inhibited by $\beta$-lactamase inhibitors (Paterson and Bonomo, 2005). ESBL-producing strains, whether clinical isolates or induced resistant strains, are not only resistant to $\beta$-lactams but also to fluoroquinolones, aminoglycosides, and florfenicol (Paterson et al., 2000; Lautenbach et al., 2001), thus constituting multi-drug resistance. AmpC $\beta$-lactamases, also called cephalosporinase, are produced by Gram-negative bacteria. The first report of plasmid-mediated AmpC $\beta$-lactamases capable of hydrolyzing penicillins, cephalosporins, and monobactams that are not inhibited by clavulanate was published in 1989 by Bauernfeind et al. In 1990, plasmid-mediated AmpC $\beta$-lactamases were characterized at the molecular level (Papanicolaou et al., 1990). Subsequently, plasmid-mediated AmpC $\beta$-lactamases have been identified worldwide. ESBL- and AmpC-producing K. pneumoniae mainly cause nosocomial infections (Bradford, 2001; Paterson and Bonomo, 2005). The present study was designed to investigate ESBLs and AmpC $\beta$-lactamases in a veterinary setting and to elucidate the evolutionary mechanism of resistance genes. Further, we emphasized the implications for veterinary clinical infections both theoretically and with respect to treatments.

\section{MATERIAL AND METHODS}

\section{Bacterial strains}

Three K. pneumoniae isolates $\left(\mathrm{K}_{1}, \mathrm{~K}_{2}, \mathrm{~K}_{3}\right)$ were collected between June 2009 and August 2009 from 2 chicken farms in Hennan Province, China. The isolates were identified as K. pneu- 
moniae using the Vitek-32 automated identification system (BioMérieux, Marcy-I'Etoile, France). The azide-resistant $E$. coli DH5 $\alpha$ (Tiangen, Beijing) was used as a recipient strain for conjugative transfer. E. coli ATCC 25922 (Beijing Ordinary Microbiology Strain Store Center), E. coli CF1124 (producing TEM-24; Peking University Health Science Center), E. coli ZM-7 (CTX-M-type, GenBank accession No. DQ849332, identified by our laboratory), and K. pneumoniae ATCC 700603 (producing SHV-18; Peking University Health Science Center) were used as reference strains.

\section{Detection of ESBLs and AmpC $\beta$-lactamase}

ESBL-producing isolates were screened by a phenotypic confirmatory test using cefotaxime, ceftazidime, cefotaxime:clavulanate (2:1), and ceftazidime:clavulanate (2:1) according to Clinical and Laboratory Standards Institute (CLSI) recommendations (Clinical and Laboratory Standards Institute, 2008b). A 30- $\mu$ g cefoxitin disc (Beijing Tiantan Drug Biotechnology, Co., Ltd.) was placed on inoculated Mueller-Hinton agar (Guangdong Huankai Microbial Sci \& Tech, Co., Ltd.). Following the CLSI criteria for non-susceptible organisms, the isolate with a zone with $<18 \mathrm{~mm}$ in diameter was selected for AmpC $\beta$-lactamase testing. For detection of AmpC, the isolate was tested using a three-dimensional extract method (Coudron et al., 2000).

\section{Antimicrobial susceptibility testing}

The antimicrobial susceptibilities of all clinical isolates were determined at the same time using a 2-fold microdilution method (Clinical and Laboratory Standards Institute, 2008a). The antimicrobial agents tested were: enrofloxacin, ciprofloxacin, levofloxacin, amoxicillin, ampicillin, imipenem, ampicillin + sulbactam (2:1), ceftriaxone, ceftiofur, cefotaxime, cefepime, doxycycline, amikacin, florfenicol, fosfomycin, colymycin, neomycin, and gentamicin. E. coli ATCC 25922 and K. pneumoniae ATCC 700603 were used as quality controls in determining minimum inhibitory concentrations (MICs). Results were interpreted in accordance with the recommendations of Clinical and Laboratory Standards Institute (2008a).

\section{DNA manipulation and identification of ESBLs and AmpC $\beta$-lactamase genes by PCR}

Since most ESBL and AmpC genes have been shown to be encoded on plasmids, plasmid DNA was extracted using a TIAN prep MiNi Plasmid Kit (Tiangen). PCR amplification of $b l a_{\mathrm{TEM}^{-}}, b l a_{\mathrm{SHV}^{-}}, b l a_{\mathrm{CTX}^{-}}{ }^{-}, b l a_{\mathrm{OXA}^{-}}, b l a_{\mathrm{ACC}^{-}}, b l a_{\mathrm{CIT}^{-}}, b l a_{\mathrm{DHA}^{-}}, b l a_{\mathrm{ACT}^{-}}, b l a_{\mathrm{FOX}^{-}}$, and $b l a_{\mathrm{MOX}^{-}}{ }^{-t y p e}$ $\beta$-lactamases was performed using plasmid DNA as a template. The different PCR primers were designed based on nucleotide sequences deposited in the NCBI/GenBank database (Table 1). The PCR samples were prepared in $50-\mu \mathrm{L}$ reaction mixtures containing $2 \mu \mathrm{L}$ plasmid DNA, $1 \mu \mathrm{L} 20$ pmoL of each primer, $25 \mu \mathrm{L}$ Premix Taq polymerase (containing reaction buffer and $\mathrm{Mg}^{2+}$ ), and $21 \mu \mathrm{L}$ deionized water. The PCR conditions were as follows: initial denaturation at $94^{\circ} \mathrm{C}$ for $5 \mathrm{~min}, 30$ cycles of denaturation at $94^{\circ} \mathrm{C}$ for $45 \mathrm{~s}$, annealing at $56^{\circ} \mathrm{C}$ for 30 $\mathrm{s}$, and extension at $72^{\circ} \mathrm{C}$ for $1 \mathrm{~min}$, a final extension step at $72^{\circ} \mathrm{C}$ for $10 \mathrm{~min}$, and pre-cooling at $4^{\circ} \mathrm{C}$ for 3 min. K. pneumoniae (ATCC700603, SHV-18), E. coli ZM-7 (CTX-M-type, GenBank accession No. DQ849332, identified by our laboratory), and E. coli (CF1124, TEM24) were used as SHV-, CTX-M-, and TEM-positive controls, respectively. The amplification products were electrophoresed on $0.8 \%$ agarose gels stained with ethidium bromide. 


\begin{tabular}{|c|c|c|c|c|c|}
\hline Target & $\begin{array}{l}\text { Primer } \\
\text { name }\end{array}$ & Primer sequence $\left(5^{\prime} \rightarrow 3^{\prime}\right)$ & $\begin{array}{l}\text { Product } \\
\text { size (bp) }\end{array}$ & $\begin{array}{c}\text { Annealing } \\
\text { temperature }\left({ }^{\circ} \mathrm{C}\right)\end{array}$ & $\begin{array}{c}\text { GenBank } \\
\text { accession No. }\end{array}$ \\
\hline \multirow[t]{2}{*}{$b l a_{\mathrm{TEM}}$} & TEM-F & GGGGATGAGTATTCAACATTTCC & \multirow[t]{2}{*}{861} & \multirow[t]{2}{*}{56} & \multirow[t]{2}{*}{ AF332513 } \\
\hline & TEM-R & GGGCAGTTACCAATGCTTAATCA & & & \\
\hline \multirow{2}{*}{$b l a_{\mathrm{SHV}}$} & SHV-F & GGTTATGCGTTATATTCGCCTGTG & \multirow[t]{2}{*}{861} & \multirow[t]{2}{*}{56} & \multirow[t]{2}{*}{ AY036620 } \\
\hline & SHV-R & TTAGCGTTGCCAGTGCTCGATCA & & & \\
\hline \multirow{2}{*}{$b l a_{\text {СTX-M }}$} & CTX-M-F & GGGCTGAGATGGTGACAAAGAG & \multirow[t]{2}{*}{861} & \multirow[t]{2}{*}{57.5} & \multirow[t]{2}{*}{ AF252622 } \\
\hline & CTX-M-R & CGTGCGAGTTCGATTTATTCAAC & & & \\
\hline \multirow{2}{*}{$b l a_{\mathrm{OXA}}$} & OXA-F & TGAAGGGTTGGGCGATTT & \multirow[t]{2}{*}{831} & \multirow[t]{2}{*}{50} & \multirow[t]{2}{*}{ AY458016 } \\
\hline & OXA-R & TTAGCGTTGCCAGTGCTCGATCA & & & \\
\hline \multirow[t]{2}{*}{$b l a_{\mathrm{ACC}}$} & ACC-F & TGTTGCTAGGGATGATTGC & \multirow[t]{2}{*}{352} & \multirow[t]{2}{*}{56} & \multirow[t]{2}{*}{ AF180952 } \\
\hline & ACC-R & GTGTATCTCACCCGATTTG & & & \\
\hline \multirow{2}{*}{$b l a_{\mathrm{CIT}}$} & CIT-F & TGCAATAACCACCCAGTCA & \multirow[t]{2}{*}{458} & \multirow[t]{2}{*}{59} & \multirow[t]{2}{*}{ EC0011291 } \\
\hline & CIT-R & GGCCCAGGCATAATCTTT & & & \\
\hline \multirow[t]{2}{*}{$b l a_{\mathrm{DHA}}$} & DHA-F & TAGTATCGGCCTGTTTGGT & \multirow[t]{2}{*}{298} & \multirow[t]{2}{*}{56} & \multirow[t]{2}{*}{ AF259520 } \\
\hline & DHA-R & CGATACATTGCAATTTCCAG & & & \\
\hline \multirow{2}{*}{$b l a_{\mathrm{ACT}}$} & ACT-F & AAGAAAGCGGAAGAGGCGCAT & \multirow[t]{2}{*}{466} & \multirow[t]{2}{*}{59} & \multirow[t]{2}{*}{ KPU58495 } \\
\hline & ACT-R & CGGGTTCGGATAGCT & & & \\
\hline \multirow{2}{*}{$b l a_{\mathrm{FOX}}$} & FOX-F & TACAGTGCGGGTGGT & \multirow[t]{2}{*}{273} & \multirow[t]{2}{*}{56} & \multirow[t]{2}{*}{ AY007369 } \\
\hline & FOX-R & GCCGTAGGCATAGTTCG & & & \\
\hline$b^{b l a} a_{\mathrm{MOX}}$ & MOX-F & CCTATGCGGTGGTCAAG & 359 & 56 & AF167990 \\
\hline & MOX-R & TGCTTCGGCACATTGAC & & & \\
\hline
\end{tabular}

\section{Cloning experiments and sequencing analyses}

PCR amplification products were purified by a TIAN gel Midi Purification Kit (Tiangen), ligated to the pGEM-T Easy vector (Promega, USA), and subsequently transformed into E. coli DH5 $\alpha$. The nucleotide and amino acid sequences were analyzed using the DNASTAR software (DNASTAR Inc., Madison, WI, USA) and the program NCBI-BLAST (http://www.ncbi.nlm.nih.gov).

\section{RESULTS}

\section{Detection of ESBLs and AmpC $\beta$-lactamase}

In screening for ESBLs, $3 \mathrm{~K}$. pneumoniae isolates were identified as suspected ESBL producers. K. pneumoniae $\mathrm{K}_{1}$ isolate was confirmed to produce ESBL. The inhibition zone diameter for discs with clavulanate was $\geq 5 \mathrm{~mm}$ larger than those without inhibitor in ceftazidime $(15 \mathrm{~mm})$, ceftazidime/clavulanate $(18 \mathrm{~mm})$, cefotaime $(14 \mathrm{~mm})$, and cefotaxime/clavulanate (21 mm). Thus, according to the CLSI criterion, the $\mathrm{K}_{1}$ isolate produced ESBLs.

Of the 3 isolates with AmpC $\beta$-lactamase, K. pneumoniae $\mathrm{K}_{1}$ isolate yielded cefoxitin zone with $<18 \mathrm{~mm}$ in diameters (screen positive). It also yielded a positive three-dimensional test, with at least 1 of the 2 surface organisms. The positive three-dimensional test result was partially reversed when a $30-\mu \mathrm{g}$ cefoxitin disk was added to the extract $(40 \mu \mathrm{L})$ prior to injection into the slit. Thus, the $\mathrm{K}_{1}$ isolate was classified as an AmpC $\beta$-lactamase-producing strain.

\section{Antimicrobial susceptibility of $\boldsymbol{K}$. pneumoniae isolated from chickens}

K. pneumoniae $\mathrm{K}_{2}$ and $\mathrm{K}_{3}$ isolates were susceptible to most antibiotics (Table 2), including cefotaxime, ceftriaxone, ceftiofur, imipenem, cefepime, colymycin, florfenicol, ami- 
kacin, neomycin, and gentamicin. In addition, a significant synergistic effect was observed on the discs of ampicillin+sulbactam. The antibacterial activity of ampicillin increased more than 8 -fold when combined with an inhibitor (sulbactam).

\begin{tabular}{|c|c|c|c|c|c|c|c|}
\hline \multirow[t]{2}{*}{ Antimicrobial agent } & \multicolumn{3}{|c|}{ MIC $(\mu \mathrm{g} / \mathrm{mL})$} & \multirow[t]{2}{*}{ Antimicrobial agent } & \multicolumn{3}{|c|}{ MIC $(\mu \mathrm{g} / \mathrm{mL})$} \\
\hline & $\mathrm{K}_{1}$ & $\mathrm{~K}_{2}$ & $\mathrm{~K}_{3}$ & & $\mathrm{~K}_{1}$ & $\mathrm{~K}_{2}$ & $\mathrm{~K}_{3}$ \\
\hline Amoxicillin & $>128$ & 128 & 128 & Colymycin & $<0.0625$ & 0.125 & 0.25 \\
\hline Ampicillin & $>128$ & $>128$ & $>128$ & Ciprofloxacin & 16 & 16 & 16 \\
\hline Enrofloxacin & 16 & 16 & 16 & Levofloxacin & 32 & 16 & 16 \\
\hline Ampicillin + sulbactam $(2: 1)^{2}$ & )$^{\mathrm{a}} \quad 128$ & 16 & 16 & Florfenicol & 32 & 1 & 4 \\
\hline Cefotaxime & 64 & $<0.0625$ & $<0.0625$ & Doxycycline & 32 & 32 & 32 \\
\hline Ceftriaxone & 64 & $<0.0625$ & $<0.0625$ & Amikacin & 64 & $<0.0625$ & $<0.0625$ \\
\hline Ceftiofur & 16 & 0.5 & 0.25 & Fosfomycin & $>128$ & 64 & 32 \\
\hline Imipenem & $<0.0625$ & 0.125 & 0.125 & Neomycin & 32 & 1 & 2 \\
\hline Cefepime & 1 & $<0.0625$ & $<0.0625$ & Gentamicin & 128 & $<0.0625$ & $<0.0625$ \\
\hline
\end{tabular}

${ }^{\text {aT }}$ The concentration of antimicrobial drugs was according to the former. MIC = minimum inhibitory concentration.

However, K. pneumoniae $\mathrm{K}_{1}$ isolate showed high levels of resistance to $\beta$-lactam antibiotics, such as penicillins, including amoxicillin (MIC $>128 \mu \mathrm{g} / \mathrm{mL}$ ) and ampicillin (MIC $>128 \mu \mathrm{g} /$ $\mathrm{mL}$ ), third-generation cephalosporins, including cefotaxime (MIC $=64 \mu \mathrm{g} / \mathrm{mL}$ ) and ceftriaxone (MIC $=64 \mu \mathrm{g} / \mathrm{mL}$ ), fluoroquinolones, including levofloxacin $(\mathrm{MIC}=32 \mu \mathrm{g} / \mathrm{mL}$ ) and ciprofloxacin ( $\mathrm{MIC}=16 \mu \mathrm{g} / \mathrm{mL}$ ), and aminoglycosides, including gentamicin $(\mathrm{MIC}=128 \mu \mathrm{g} / \mathrm{mL}$ ), and amika$\operatorname{cin}(\mathrm{MIC}=64 \mu \mathrm{g} / \mathrm{mL})$. The activity of ampicillin was not enhanced by the addition of sulbactam, so the isolate was also resistant to ampicillin. In addition, $K$. pneumoniae $\mathrm{K}_{1}$ isolate had a multidrug phenotype, suggesting that $K$. pneumoniae $\mathrm{K}_{1}$ isolate probably acquired additional resistance genes. In order to better understand their genetic relationships, further studies must characterize the plasmids on which bla genes and other resistance genes are located (Yuan et al., 2009).

\section{PCR amplification of ESBLs and AmpC $\beta$-lactamase genes}

Using plasmids from the K. pneumoniae isolates, PCR with primers specific for $b l a_{\mathrm{TEM}}$, $b l a_{\mathrm{SHV}}$ and $b l a_{\mathrm{CTX-M}}$ resulted in a band of approximately $861 \mathrm{bp}$, which was consistent with the predicted size. The plasmids from $\mathrm{K}_{2}$ and $\mathrm{K}_{3}$ isolates only displayed the TEM-type band. None of the plasmids amplified bands corresponding to the OXA-type sequence. For AmpC $\beta$-lactamase genes, the plasmids of $\mathrm{K}_{1}$ isolate only displayed bands corresponding to ACT-type sequences. On the other hand, the plasmids of $\mathrm{K}_{2}$ and $\mathrm{K}_{3}$ isolates did not display AmpC $\beta$-lactamase genes.

\section{Sequences analysis of ESBL and AmpC $\beta$-lactamase genes}

The sequence analysis revealed that $3 \mathrm{~K}$. pneumoniae isolates harbored identical TEMtype nucleotide sequences. The $b l a_{\text {TEM }}$ genes were identical (GenBank accession No. AY293072). The $b l a_{\mathrm{TEM}}$-type gene was designated as TEM-1. In addition, K. pneumoniae $\mathrm{K}_{1}$ isolate also harbored SHV-type and CTX-M-type nucleotide sequences. The SHV-type gene was 99\% identical at the nucleotide level to SHV-11 (GenBank accession No. GU064388), which was discovered in Brazil. Specifically, there was only a single nucleotide difference between the sequences. A change from $\mathrm{G}$ to $\mathrm{C}$ at position 720 , which resulted in a silent mutation in the amino acid 
sequence. Therefore, the $b l a_{\mathrm{SHV}}$-type sequence was designated as SHV-11. The $b l a_{\mathrm{CTX}-\mathrm{M}}$ genes were identical as well (GenBank accession No. EF416289). Therefore, the bla CTX-M $^{\text {-type se- }}$ quence was designated as CTX-M-14. The sequence analysis showed that only $K$. pneumoniae $\mathrm{K}_{1}$ isolate harbored ACT-type AmpC $\beta$-lactamase nucleotide sequences. There were differences in 8 nucleotides between the ACT-type and the ACT-like sequences (GenBank accession No. EF078894). These mutations were $\mathrm{A}^{75} \mathrm{G}, \mathrm{C}^{84} \mathrm{G}, \mathrm{T}^{90} \mathrm{C}, \mathrm{A}^{105} \mathrm{G}, \mathrm{G}^{213} \mathrm{~A}, \mathrm{G}^{246} \mathrm{~A}, \mathrm{C}^{309} \mathrm{~T}$, and $\mathrm{T}^{315} \mathrm{C}$. The deduced amino acid sequence revealed that the mutations at positions 84, 90, 105, 213, 246, 309, and 315 were silent mutations. The mutation at position 75 led to an amino acid substitution of Asn28Lys. Thus, the $b l a_{\mathrm{ACT}}$-type sequence was classified as an ACT-like derivative.

The nucleotide sequence of $b l a_{\mathrm{SHV}}, b l a_{\mathrm{CTX}-\mathrm{M}}$, and $b l a_{\mathrm{ACT}}$ reported in this study appear under GenBank accession Nos. GU211012, GU211011, and GU211014, respectively.

\section{DISCUSSION}

With the extensive use of $\beta$-lactam antibiotics, such as penicillins and cephalosporins, in the control of bacterial diseases in veterinary clinics, especially the informal use of thirdgeneration cephalosporins, such as ceftiofur, ceftriaxone, and cefotaxime, bacterial drug-resistance has become increasingly severe and has complicated clinical treatment. The decreased efficacy of cephalosporins against Gram-negative bacteria results from the production of AmpC $\beta$-lactamases or ESBLs, which has complicated veterinary clinical treatment. In this study, the susceptibility test results showed that the ESBL-producing and AmpC $\beta$-lactamase-producing $K$. pneumoniae $\mathrm{K}_{1}$ isolate was resistant not only to third-generation cephalosporins, such as cefotaxime and ceftriaxone, but also to other antimicrobial drug classes, such as fluoroquinolones (levofloxacin and ciprofloxacin) and aminoglycosides (gentamicin and amikacin). K. pneumoniae $\mathrm{K}_{1}$ isolate has characteristics of cross-resistance and multidrug resistance to antibiotics.

When an isolate is confirmed to produce ESBL based on the CLSI-recommended phenotypic confirmatory test, it is considered to be resistant to all penicillins, cephalosporins, and aztreonam. Therefore, the detection of ESBL must be improved. Once an isolate is found to produce ESBLs, it should be reported as resistant to $\beta$-lactam antibiotics, regardless of its MIC in susceptibility tests in vitro (Hu et al., 2008). However, at present, there are no approved criteria for AmpC detection (Doi and Paterson, 2007). In this study, the susceptibility test results demonstrated that the use of combinations of $\beta$-lactam antibiotics and $\beta$-lactamase inhibitors were used, such as ampicillin and sulbactam, MICs were decreased compared to those of $\beta$-lactams alone. Thus, the $\beta$-lactamase inhibitor (sulbactam) enhanced the antibacterial activity of $\beta$-lactam antibiotics. As such, compound preparations of $\beta$-lactam antibiotics and $\beta$-lactamase inhibitors may be valuable in practical applications. Although in vitro tests suggest that ESBLs are inhibited by $\beta$-lactamase inhibitors, such as clavulanic acid and sulbactam, the activity of $\beta$-lactamase inhibitor combination agents is influenced by the bacterial inoculum, dose and administration regimen, and specific type of ESBL. Further, antibacterial choice is often complicated by multi-drug resistance. Many ESBL-producing organisms also express AmpC $\beta$-lactamases and may be co-transferred with plasmids mediating aminoglycoside resistance. In addition, there is a positive association between ESBL production and fluoroquinolone resistance. Currently, carbapenems (imipenem), cefepime, and colymycin are considered firstline agents for infections caused by ESBL-producing or AmpC-producing bacteria.

Since the first ESBL was reported from K. pneumoniae in 1983, ESBL-producing En- 
terobacteriaceae have been reported worldwide. Recently, genotypes and subtypes of ESBL-producing and AmpC $\beta$-lactamase-producing have been reported from several different countries: TEM-1- and SHV-11 $\beta$-lactamase-producing K. pneumoniae strains were isolated from Switzerland (Lartigue et al., 2007); CTX-M-14 ESBL-producing K. pneumoniae and Enterobacter cloacae strains were isolated from Egypt (Khalaf et al., 2009); CTX-M-15 ESBL-, TEM-1-, and SHV$11 \beta$-lactamase-producing K. pneumoniae strains were reported in Iran (Feizabadi et al., 2010); ACT-1 AmpC-producing K. pneumoniae strains were first reported in America (Bradford et al., 1997); ACT-1 and FOX-5 AmpC-producing K. pneumoniae strains were isolated from America (Coudron et al., 2003), and ACT-3 AmpC-producing K. pneumoniae strains were isolated from China (Chen et al., 2009). SHV-type ESBL-producing K. pneumoniae strains and ACT-1-type AmpC-producing K. pneumoniae strains were isolated from New Jersey (Queenan et al., 2004); TEM- and SHV-type ESBL-producing K. pneumoniae strains and ACT-1-type AmpC-producing K. pneumoniae strains were isolated from the United States (Tenover et al., 2009).

Pathogens producing ESBLs and transferable AmpC $\beta$-lactamases are an increasing cause of concern in veterinary medicine. Therefore, it is vital for clinical laboratories to be able to detect these enzymes. This will ensure that animals receive appropriate antibiotic therapy and that infection control efforts are effective.

In this study, we reported a single strain of $K$. pneumoniae, $\mathrm{K}_{1}$ isolate, that produced CTX-M-14-type ESBL and an ACT-like derivative AmpC $\beta$-lactamase together with SHV-11 and TEM-1 $\beta$-lactamases isolated from chickens in Henan Province, China. The sequence analysis showed that $3 \mathrm{~K}$. pneumoniae isolates harbored identical TEM-type nucleotide sequences. As such, the $b l a_{\text {TEM }}$-type sequence was designated as TEM-1. In addition, the sequence analysis showed that K. pneumoniae $\mathrm{K}_{1}$ isolate also harbored SHV-type and CTX-M-type nucleotide sequences; the $b l a_{\mathrm{SHV}}$-type sequence was designated as SHV-11, and the $b l a_{\mathrm{CTX}-\mathrm{M}}$-type sequence was designated as CTX-M-14. SHV-11 has been reported to be the most common sequence among K. pneumoniae isolates causing outbreaks (Ko et al., 2008). The present sequence analysis showed that only $K$. pneumoniae $\mathrm{K}_{1}$ isolate harbored ACT-type AmpC $\beta$-lactamasenucleotide sequences. The deduced amino acid sequence revealed silent mutations at positions 84, 90, 105, 213, 246, 309, and 315, while the mutation at position 75 led to an amino acid substitution (Asn28Lys). The $b l a_{\mathrm{ACT}}$-type sequence was an ACT-like derivative. This is the first report of an ACT-like derivative in a K. pneumoniae isolate from chicken in Henan Province, China.

In summary, ESBL-producing and AmpC-producing genes were usually encoded by a plasmid carrying multiple genes conferring resistance to other antimicrobial agents. This further complicates the clinical treatment of such bacterial infections. Therefore, it is important to closely monitor ESBL-producing and AmpC-producing strains and to prevent their spread.

\section{ACKNOWLEDGMENTS}

Research supported by a grant from the National Natural Science Foundation of China (\#30771624) and Key Laboratory for Animal-Derived Food Safety of Henan Province.

\section{REFERENCES}

Bauernfeind A, Chong Y and Schweighart S (1989). Extended broad spectrum $\beta$-lactamase in Klebsiella pneumoniae including resistance to cephamycins. Infection 17: 316-321.

Bradford PA (2001). Extended-spectrum $\beta$-lactamases in the 21st century: characterization, epidemiology, and detection 
of this important resistance threat. Clin. Microbiol. Rev. 14: 933-51.

Bradford PA, Urban C, Mariano N, Projan SJ, et al. (1997). Imipenem resistance in Klebsiella pneumoniae is associated with the combination of ACT-1, a plasmid-mediated AmpC $\beta$-lactamase, and the foss of an outer membrane protein. Antimicrob. Agents Chemother. 41: 563-569.

Chen Y, Cheng J, Wang Q, Ye Y, et al. (2009). ACT-3, a novel plasmid-encoded class C $\beta$-lactamase in a Klebsiella pneumoniae isolate from China. Int. J. Antimicrob. Agents 33: 95-96.

Clinical and Laboratory Standards Institute (2008a). Performance Standards for Antimicrobial Susceptibility Testing, 18th Informational Supplement (M100-S16) CLSI. Wayne.

Clinical and Laboratory Standards Institute (2008b). Performance Standards for Antimicrobial Disk and Dilution Susceptibility Tests for Bacteria Isolated from Animals Approved Standard. 3rd edn. (M31-A3) CLSI, Wayne.

Coudron PE, Moland ES and Thomson KS (2000). Occurrence and detection of AmpC $\beta$-lactamases among Escherichia coli, Klebsiella pneumoniae, and Proteus mirabilis isolates at a veterans medical center. J. Clin. Microbiol. 38: 1791-1796.

Coudron PE, Hanson ND and Climo MW (2003). Occurrence of extended-spectrum and AmpC $\beta$-lactamases in bloodstream isolates of Klebsiella pneumoniae: isolates harbor plasmid-mediated FOX-5 and ACT-1 AmpC $\beta$-lactamases. J. Clin. Microbiol. 41: 772-777.

De Champs C, Sirot D, Chanal C, Bonnet R, et al. (2000). A 1998 survey of extended-spectrum $\beta$-lactamases in Enterobacteriaceae in France. The French Study Group. Antimicrob. Agents Chemother. 44: 3177-3179.

Doi Y and Paterson DL (2007). Detection of plasmid-mediated class C $\beta$-lactamases. Int. J. Infect. Dis. 11: 191-197.

Feizabadi MM, Delfani S, Raji N, Majnooni A, et al. (2010). Distribution of $b l a_{\mathrm{TEM}}, b l a_{\mathrm{SHV}}, b l a_{\mathrm{CTX}-\mathrm{M}}$ genes among clinical isolates of Klebsiella pneumoniae at Labbafinejad Hospital, Tehran, Iran. Microb. Drug Resist. 16: 49-53.

Hu GZ, Chen HY, Si HB, Deng LX, et al. (2008). Phenotypic and molecular characterization of TEM-116 extended-spectrum $\beta$-lactamase produced by a Shigella flexneri clinical isolate from chickens. FEMS Microbiol. Lett. 279: 162-166.

Khalaf NG, Eletreby MM and Hanson ND (2009). Characterization of CTX-M ESBLs in Enterobacter cloacae, Escherichia coli and Klebsiella pneumoniae clinical isolates from Cairo, Egypt. BMC Infect. Dis. 9: 84.

Ko KS, Yeom JS, Lee MY, Peck KR, et al. (2008). Clonal dissemination of extended-spectrum $\beta$-lactamase (ESBL)producing Klebsiella pneumoniae isolates in a Korean hospital. J. Korean Med. Sci. 23: 53-60.

Lartigue MF, Zinsus C, Wenger A, Bille J, et al. (2007) Extended Spectrum $\beta$-Lactamases of the CTX-M type now in Switzerland. Antimicrob. Agents Chemother. 51: 2855-2860.

Lautenbach E, Strom BL, Bilker WB, Patel JB, et al. (2001). Epidemiological investigation of fluoroquinolone resistance in infections due to extended-spectrum $\beta$-lactamase-producing Escherichia coli and Klebsiella pneumoniae. Clin. Infect. Dis. 33: 1288-1294.

Lavigne JP, Bonnet R, Michaux-Charachon S, Jourdan J, et al. (2004). Post-antibiotic and post- $\beta$-lactamase inhibitor effects of ceftazidime plus sulbactam on extended-spectrum $\beta$-lactamase-producing Gram-negative bacteria. $J$. Antimicrob. Chemother. 53: 616-619.

Papanicolaou GA, Medeiros AA and Jacoby GA (1990). Novel plasmid-mediated $\beta$-lactamase (MIR-1) conferring resistance to oxyimino- and alpha-methoxy $\beta$-lactams in clinical isolates of Klebsiella pneumoniae. Antimicrob. Agents Chemother. 34: 2200-2209.

Paterson DL and Bonomo RA (2005). Extended-spectrum $\beta$-lactamases: a clinical update. Clin. Microbiol. Rev. 18: 657-686.

Paterson DL, Mulazimoglu L, Casellas JM, Ko WC, et al. (2000). Epidemiology of ciprofloxacin resistance and its relationship to extended-spectrum $\beta$-lactamase production in Klebsiella pneumoniae isolates causing bacteremia. Clin. Infect. Dis. 30: 473-478.

Queenan AM, Foleno B, Gownley C, Wira E, et al. (2004). Effects of inoculum and $\beta$-lactamase activity in AmpC- and extended-spectrum $\beta$-lactamase (ESBL)-producing Escherichia coli and Klebsiella pneumoniae clinical isolates tested by using NCCLS ESBL methodology. J. Clin. Microbiol. 42: 269-275.

Sirot D (1995). Extended-spectrum plasmid-mediated $\beta$-lactamases. J. Antimicrob. Chemother. 36 Suppl A: 19-34.

Tenover FC, Emery SL, Spiegel CA, Bradford PA, et al. (2009). Identification of plasmid-mediated AmpC $\beta$-lactamases in Escherichia coli, Klebsiella spp., and proteus species can potentially improve reporting of cephalosporin susceptibility testing results. J. Clin. Microbiol. 47: 294-299.

Winokur PL, Canton R, Casellas JM and Legakis N (2001). Variations in the prevalence of strains expressing an extendedspectrum $\beta$-lactamase phenotype and characterization of isolates from Europe, the Americas, and the Western Pacific region. Clin. Infect. Dis. 32 Suppl 2: S94-103.

Yuan L, Liu JH, Hu GZ, Pan YS, et al. (2009). Molecular characterization of extended-spectrum $\beta$-lactamase-producing Escherichia coli isolates from chickens in Henan Province, China. J. Med. Microbiol. 58: 1449-1453. 